\title{
Comparative assessment of scoring methods to evaluate the conservation value of pond and small lake biodiversity
}

\author{
V. ROSSET ${ }^{\mathrm{a}, *, \dagger}$, J. P. SIMAIKA ${ }^{\mathrm{b}, \mathrm{c}}$, F. ARTHAUD $^{\mathrm{d}, \mathrm{e}}$, G. BORNETTE $^{\mathrm{d}, \mathrm{e}}$, D. VALLOD $^{\mathrm{d}, \mathrm{e}}$, M. J. SAMWAYS ${ }^{\mathrm{b}}$ and B. OERTLI $^{\mathrm{a}}$ \\ ${ }^{a}$ University of Applied Sciences Western Switzerland, hepia Geneva technology, architecture and landscape, 1254 Jussy-Geneva, Switzerland \\ ${ }^{\mathrm{b}}$ Stellenbosch University, Department of Conservation Ecology and Entomology, P Bag X1, Matieland 7602, South Africa \\ ${ }^{\mathrm{c}}$ Department of River Ecology and Conservation, Biodiversity and Climate Research Centre and Senckenberg Research Institute and \\ Natural History Museum Frankfurt, 63571 Gelnhausen, Germany \\ dISARA-Lyon, 69364 Lyon, France \\ ${ }^{\mathrm{e}}$ Lyon University, 69003 Lyon, France; Lyon 1 University, 69622 Villeurbanne, France; ENTPE, 69518 Vaulx-en-Velin, France; \\ CNRS, UMR5023 «Laboratory of ecology of natural and anthropised hydrosystems », 69622 Villeurbanne, France
}

\begin{abstract}
1. Fresh waters are among the most endangered ecosystems in the world. Practical tools to measure their biodiversity value are needed for their effective conservation. Besides species richness, other aspects of biodiversity, including the threat level of species also need to be considered. Currently, existing scoring methods for assessing the conservation value of freshwater fauna and flora assemblages are varied, and guidelines to select an appropriate method are lacking.

2. In this paper, it is hypothesized that scores to assess the conservation value of assemblages can vary markedly according to the type of method used. To test this, four types of scoring methods were applied differing in the weight given to Red List categories and in the expression of the score, i.e. either using mean per species or the assemblage as a whole, on sets of dragonfly and macrophyte data collected from varied types of small lakes and ponds in three different countries (France, Switzerland and South Africa).

3. The comparison of the different types of methods showed that the type of method used had a marked impact on the assessment of the conservation value of a water body: the expression per species or per assemblage as the weight given to Red List categories changed the value of a given water body.

4. Overall, results also confirmed that the different types of methods could be applicable in different geographical areas and types of standing water bodies, independently of the original area where the method was developed.

5. Results illustrated that, besides the species richness assessment commonly used, calculating conservation value as a mean per species is useful because it provides additional information. Overall, using methods expressed as a mean per species and coupling the Red List with other criteria gave the best performance. Copyright (C) 2012 John Wiley \& Sons, Ltd.
\end{abstract}

Received 9 December 2011; Revised 1 July 2012; Accepted 8 August 2012

KEY WORDS: freshwater ecosystems; Red List; species richness; dragonflies; macrophytes; biotope quality

\footnotetext{
*Correspondence to: Véronique Rosset, University of Applied Sciences Western Switzerland, hepia Geneva technology, architecture and landscape, 1254 Jussy-Geneva, Switzerland. E-mail: veronique@rosset.org

†Present address: Geneva University, Institute for Environmental Sciences, 1227 Carouge, Switzerland.
} 


\section{INTRODUCTION}

Fresh waters are among the most threatened ecosystems worldwide (Ricciardi and Rasmussen, 1999; Millennium Ecosystem Assessment, 2005). This is particularly true for ponds and small lakes, which are threatened by habitat loss, excessive nutrient load, chemical pollution, climate change, and invasion by alien species (Brönmark and Hansson, 2002; EPCN, 2007). Ponds and small lakes are numerous across many landscapes (Downing et al., 2006). They form networks essential to the meta-populations of many species and provide important ecological, social, and economic services such as wildlife habitat, livestock watering, fish production or recreational activities (Jeffries, 2005; EPCN, 2007). At the regional scale, they collectively support diverse, and in some cases unique biodiversity, often richer than that in running waters or large lakes (Williams et al., 2004; Biggs et al., 2005; Angelibert et al., 2006).

The conservation of biodiversity faces limited resources in time, funding and personnel (Kati et al., 2004) and needs effective, practical tools for measuring the conservation value of biodiversity. In ecology, one of the most commonly used measures of biodiversity is species richness (Magurran, 2004; Fleishman et al., 2006). However, measures based on species richness alone have the disadvantage of not taking into account species composition and therefore the level of threat to, or endemism among, the species present in a community.

Standardized scoring methods have been developed for the assessment of the conservation value of fresh waters worldwide. These use different combinations of physical and/or biological criteria (Boon and Pringle, 2009). The most used biological criterion (see among the selection of representative scoring methods in Table 1) is the IUCN Red List Categories (IUCN, 2001), hereafter referred to as the 'Red List'. Methods to assess the conservation value of fauna and flora assemblages, hereafter referred to as 'conservation value', are regionally diverse, with no consensus on a unified strategy. For example, all the existing scoring methods described in Table 1 have been developed for specific countries and have rarely been tested in other geographical areas.

One important difference among existing scoring methods that assess the conservation value is the weight they give to the Red List. Some methods are based exclusively on the Red List. For example the species quality score (SQS), developed by Foster et al. (1989), is based solely on the Red List for water beetles in the UK. The SQS concept has since been applied to other taxa in a variety of freshwater systems, from lentic to lotic, in the UK (Painter, 1999; Nicolet et al., 2004; Williams et al., 2004), France (Oertli, 1995; Godreau et al., 1999), and Switzerland (Oertli et al., 2002). Other methods which use the Red List, but also other biological and/or physical criteria include, for example, the Community Conservation Index (CCI), the Swedish System Aqua, the Dragonfly Biotic Index (DBI), the Lake Assessment for Conservation system (LACON) and the System for Evaluating Rivers for Conservation (SERCON). The CCI is used in the UK to assess the conservation value of freshwater invertebrate communities (Chadd and Extence, 2004). System Aqua uses the Red List threat level, naturalness of the catchment and species richness to assess the conservation value of seven freshwater and terrestrial groups (Willen, 2009). The DBI, developed for South African freshwater systems, also uses the Red List in combination with other criteria, in this case the geographical extent of species and the sensitivity of species to habitat disturbance (Samways, 2008; Simaika and Samways, 2009a). The LACON system (Duker and Palmer, 2009) and the SERCON system (Boon et al., 1997; Boon, 2000; Boon et al., 2002), developed in the UK, use the Red List in combination with many other biological criteria, such as the naturalness of the species assemblages, as well as in combination with physical criteria, such as the naturalness of the flow regime. Some scoring methods do not make use of the Red List at all, and focus rather on ecosystem health applying a combination of geomorphological, hydrological and ecological criteria (Amoros et al., 2000), or biological indicators as, for example, the Index of Centres of Density (ICD) developed in the USA by Angermeier and Winston (1997), which uses the number of source populations in an area to assess the conservation value of fish assemblages. Another method, independent of the Red List, has been developed in France for terrestrial plants, assessing the conservation value based on a combination of local rarity, regional rarity, and habitat vulnerability criteria (Gauthier et al., 2010).

Scoring methods to assess the conservation value of freshwater assemblages are expressed at different levels, either (i) the assemblage ('per assemblage'), or (ii) the species ('per species'), often a statistical 
ASSESSMENT OF CONSERVATION VALUE OF POND AND SMALL LAKE BIODIVERSITY

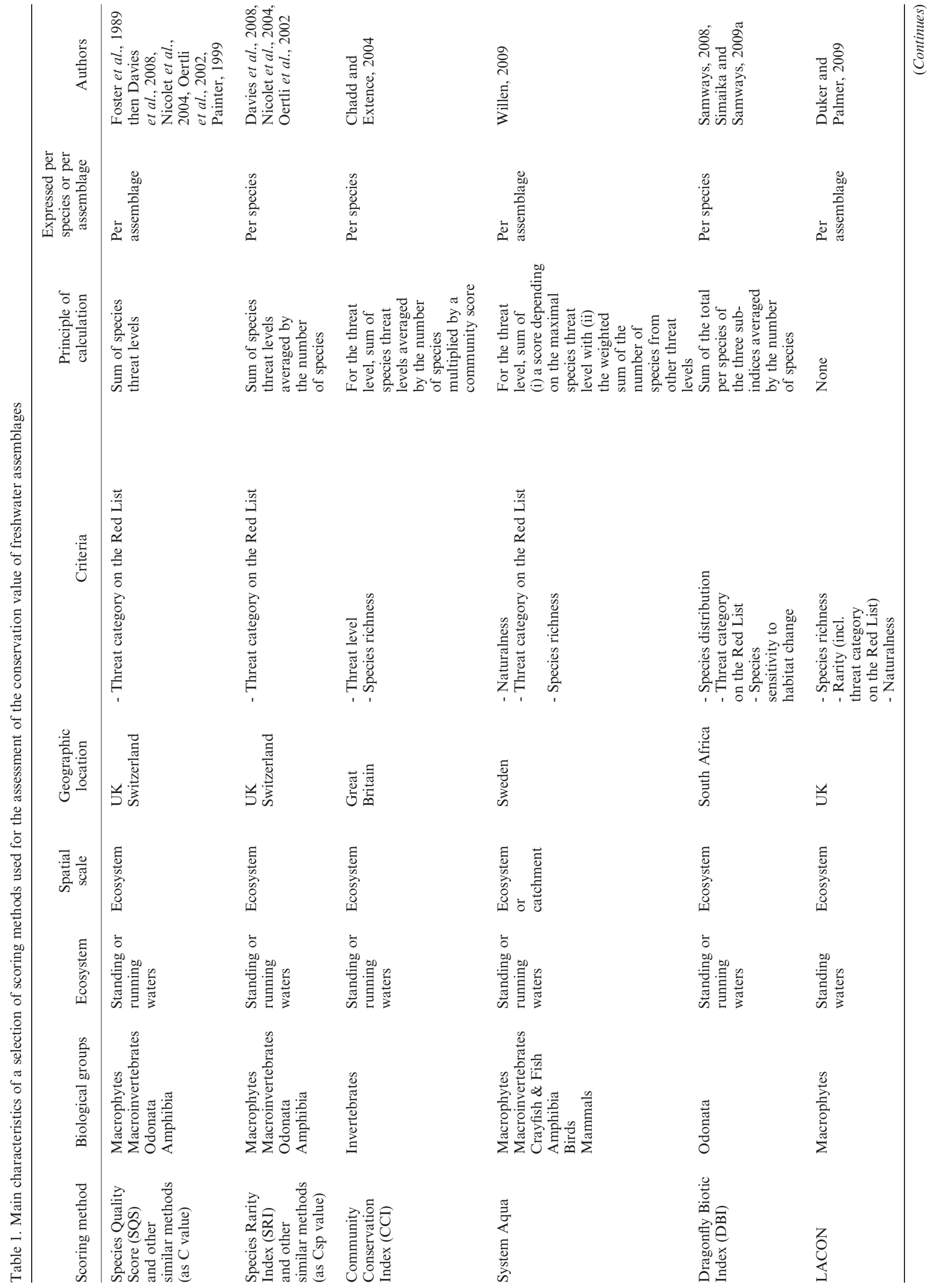




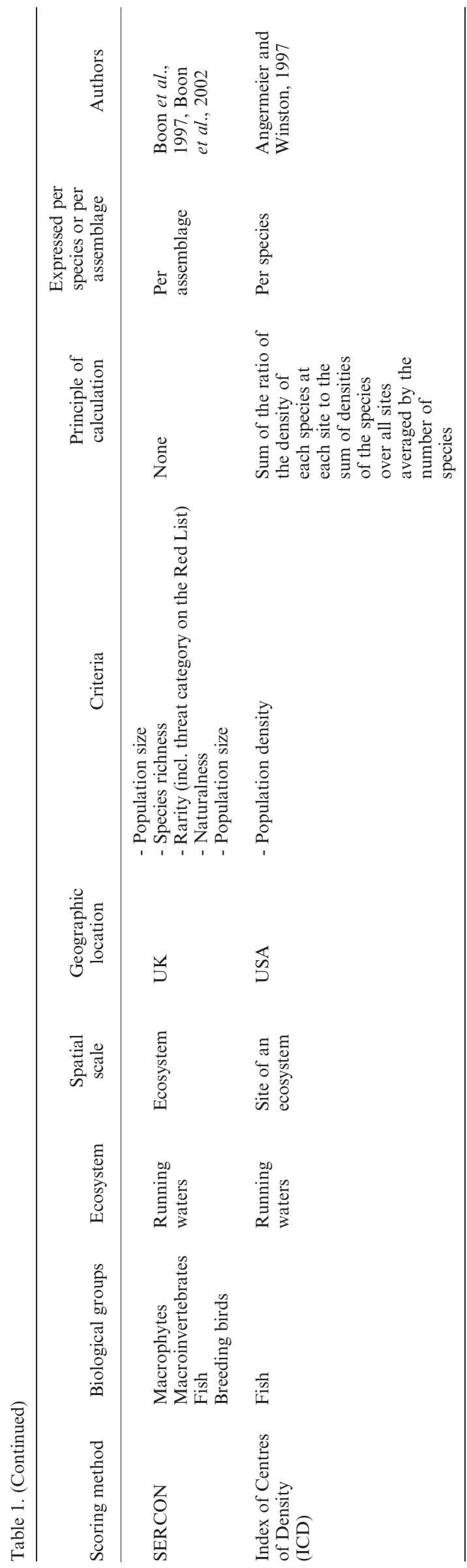

mean of the species belonging to the assemblage (Table 1). For example the SQS is expressed per assemblage, as it consists of the sum of the threat levels of all species belonging to the assemblage. An adaptation of the SQS, the Species Rarity Index (SRI) is, in contrast, expressed per species, and consists of the sum of the threat levels of all species belonging to the assemblage (i.e. the SQS) averaged by the number of species.

These many different types of methods can be confusing for nature conservation managers and environmental consultants, and could potentially lead to different management recommendations. The main aim here is therefore to clarify the differences between the types of methods in order to help the choice of method best tailored to any particular situation.

Our central hypothesis is that assessment of the conservation value of pond and small lake assemblages differs markedly depending on the type of method used, i.e. according to the weight given to the Red List and the expression of the score, whether using a mean per species or the assemblage as a whole. This hypothesis was tested by (i) analysing the differences between the conservation values given by different types of methods for the same assemblages (macrophytes or dragonflies) in order to identify potential redundancy or complementarity, and (ii) identifying the potential of different types of methods to provide additional information over species richness. Moreover, in order to clarify further the differences between the types of methods, some were tested to see if they could provide an additional tool to species richness estimates for evaluating biotope quality.

Another objective of this study was to confirm the applicability of a given method in different geographical areas and for different types of water bodies, independently of the original area and water bodies for which the method was developed.

\section{MATERIAL AND METHODS}

\section{Biodiversity data sets}

Water bodies from three different geographical areas were selected, two areas in Europe (France and Switzerland) and one in Africa (South Africa) (Figure 1, Table 2). In France (Figure 1(A)), 78 ponds located in a dense network of an area of $1000 \mathrm{~km}^{2}$ (the Dombes region, north east from 


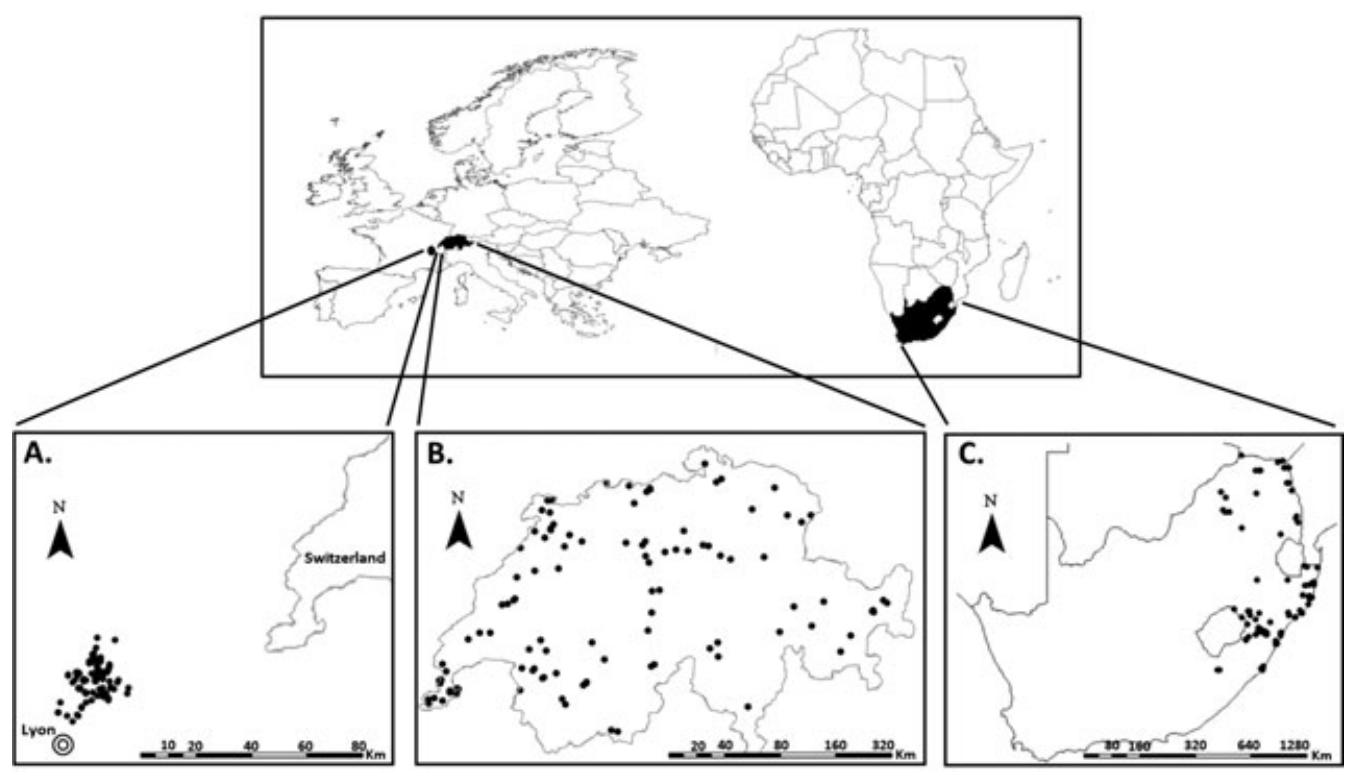

Figure 1. Location of the three study areas in Europe and Africa and location of the 623 sites studied: (A) in Dombes region of France, (B) in Switzerland, and (C) in South Africa.

Lyon), were studied during a project aiming at assessing the ecological value of fish ponds (Vallod et al., 2011; Arthaud et al., ). In Switzerland (Figure 1(B)), 90 ponds and small lakes scattered throughout the country were studied in the context of various projects (Oertli et al., 2002; Indermuehle et al., 2010; Menetrey et al., 2010). In South Africa (Figure 1(C)), 116 ponds and reservoirs scattered throughout the eastern part of the country were studied. The data consisted of systematic records from museum and private collections and sightings (from 1901 to present) (Simaika and Samways, 2009b).

Adult dragonflies (Odonata) and macrophytes were studied using presence/absence data. These two groups were chosen because data on adult dragonflies were available for all water bodies in the three countries, and data were available on macrophytes for all water bodies in Switzerland and for about two-thirds of the water bodies in France (55 of the 78 ponds).

\section{Scoring methods for conservation value}

The conservation value of dragonfly and macrophyte assemblages of small water bodies was assessed with four different types of methods distinguished by the weight given to the Red List and their expression, whether per species or per assemblage (see Introduction).

Scoring methods based exclusively on the Red List and expressed per assemblage

The first type of method was based exclusively on the Red List and expressed per assemblage. Two examples are used here: the $\mathrm{C}$ value (Oertli et al., 2002) and the rarity component of the Swedish System Aqua (Willen, 2009).

Table 2. Description of the three biodiversity data sets: France, Switzerland and South Africa

\begin{tabular}{llll}
\hline & \multicolumn{1}{c}{ France } & \multicolumn{1}{c}{ Switzerland } & South Africa \\
\hline Number of ponds studied & 76 & 90 & 116 \\
Median pond area (min-max) $\left[\mathrm{m}^{2}\right]$ & $9580(1840-86500)$ & $2270(6-96000)$ & $640(4-110000)$ \\
Median pond depth [m] & 0.65 & 1.15 & 0.8 \\
Range of altitude [m. a.s.l] & $265-310$ & $210-2760$ & $0-2300$ \\
Range of nutrient load & eutrophic to hypertrophic & oligotrophic to hypertrophic & mesotrophic to hypertrophic \\
Origin & artificial & artificial and natural & mostly artificial \\
Main uses & fish farming & nature conservation & watering points for game or \\
& & recreation & domestic livestock \\
& & irrigation & fravel or clay extraction \\
& & fish farming & recreational fishing \\
\hline
\end{tabular}


The $\mathrm{C}$ conservation value is an application (Oertli et al., 2002) equivalent to the SQS (Foster et al., 1989, 1992; Painter, 1999; Williams et al., 2004; Davies et al., 2008; Copp et al., 2010) which ranks species according to their degree of rarity on the national Red List in geometric progression, successively doubling from 1 (commonest species) to 32 (rarest). The conservation value per site of the species assemblage ( $\mathrm{C}$ value) is the sum of the scores of all species present at the site.

The rarity component of System Aqua, hereafter named the 'Aqua method', consists of a weighted value ranging from 0 to 5 based on species' threat status on the national Red List (for the exact formula, see Willen, 2009).

Scoring method based exclusively on the Red List and expressed per species: the Csp value

The second type of method is based also exclusively on the Red List, but expressed per species. The example of the Csp value is used here. The Csp conservation value is an application (Oertli et al., 2002) of the Species Rarity Index developed in the UK (Williams et al., 1998). As for the $\mathrm{C}$ value, species are ranked according to their degree of rarity on the national Red List following the same geometric progression as the $\mathrm{C}$ value. The mean conservation value per site per species (Csp value) is the $\mathrm{C}$ value divided by the number of species present in the site.

Scoring method coupling the Red List with other criteria and expressed per species: the Dragonfly Biotic Index

The third type of method couples the Red List with other criteria and is expressed per species. The example of the South African Dragonfly Biotic Index (DBI) (Samways, 2008; Simaika and Samways, 2009a) is used here.

The DBI is a composite index that consists of three sub-indices: species geographical distribution in the investigated area, threat status based on the national and global Red List, and species sensitivity to habitat disturbance (Simaika and Samways, 2009a). Disturbance, in the sense of the DBI sub-index, refers here to human disturbance, whether direct or indirect - for example, habitat degradation by invasion of alien species, cattle trampling, over-abstraction, and agricultural runoff. The DBI score per site, which originally consisted of the sum of the total per species of three sub-indices averaged by the total number of species and ranges from 0 to 3 , was slightly modified in Switzerland and France. First, the mean of the three sub-indices was used instead of the sum, because of lack of data for one of the three sub-indices for some species. Then, the weightings of the sub-indices were replaced by a continuous gradient ranging from 0 to 1 , so that the DBI score ranged from 0 to 1 , rather than 0 to 3 .

The need for information on species, geographical distribution in the investigated area and species sensitivity to habitat disturbance makes the DBI longer to compute compared with the methods based exclusively on the Red List. However, once the DBI is calculated, it is, for practical purposes, virtually permanent (Samways, 2008). The DBI allows the classification of species of Least Concern (LC), and so a more precise classification of sites with only LC species than other methods based exclusively on the Red List.

\section{Scoring method independent of the Red List and} expressed per species: the nested ranking method

The fourth type of method includes those methods that are independent of the Red List, and expressed per species. The example of the French 'nested ranking system', developed by Gauthier et al. (2010), is used here. This method is based on three criteria: regional rarity, local rarity and habitat vulnerability and classifies the species according to a hierarchical approach, where the regional rarity criterion is first order, the local rarity a nested criterion of second order and habitat vulnerability a criterion of third order. The first criterion, regional rarity, corresponds to the extent of the species' geographical distribution outside the study area, while the second criterion, local rarity, corresponds to the extent of the geographical distribution inside the study area. The third criterion provides information on the likelihood of habitat loss for a given species in the study region. The initial nested ranking method was slightly modified from weightings ranging from 0 to 5 to a continuous gradient of values rounded off to the first decimal place, and ranging from 0 to 1 . To obtain a nested ranking per site, the same standardization procedure was applied as in the DBI, in which the total of all species ranks is divided by the total number of species.

As with the DBI, the need for information on species' geographical distribution and species' habitat vulnerability makes the nested ranking method longer to compute in comparison with the 
methods based exclusively on the Red List. This method also has in common with the DBI the ability to classify sites where all the species are of Least Concern more precisely than other methods based exclusively on the Red List. The nested ranking method does not consider changes in species' population sizes at a global scale, whereas the other methods indirectly incorporate this criterion through the Red List.

\section{Data sources for the calculation of conservation values}

The conservation values given by all scoring methods were calculated for adult dragonflies of South Africa and for adult dragonflies and macrophytes of France and Switzerland.

All scoring methods, except the nested ranking method, required the national Red List. Red Lists were available for both dragonflies and macrophytes in Switzerland (Gonseth and Monnerat, 2002; Moser et al., 2002; Auderset Joye et al., 2010) and for dragonflies in South Africa (Samways, 2006). In France, no Red List is currently available for dragonflies and macrophytes, so the Swiss Red Lists were used as a surrogate because of geographical proximity (see Figure 1(A)), species pool similarity (90\% of the recorded French macrophyte and dragonfly species are present in Switzerland), and threat similarity (e.g. habitat loss, climate change, pollution).

The extent of species' geographical distribution within the study area was required for both DBI and the nested ranking method. In Switzerland, it was quantified for both biological groups by the number of grid cells of $20 \times 20 \mathrm{~km}$ where a species is present (data from the Swiss Biological Records Center (CSCF), and the Swiss Floristic Records Center (CRSF)). In France, it was quantified using the frequency of occurrence of each species among the shallow lakes studied. In South Africa, the species' geographical distribution was scored from 0-3 with 0 for a species occurring throughout southern Africa and 3 for an endemic species on the basis of an unpublished dragonfly database (Simaika and Samways, 2009a).

The nested ranking method requires the quantification of the species' geographical distribution beyond the study area, i.e. in Europe for the Swiss data set, in Africa for the South African data set, and in France for the French data set, which consists only of a small portion of the country (see Figure 1(A)). For the dragonflies of Switzerland, it was quantified based on the presence of species in $500 \mathrm{~km} \times 500 \mathrm{~km}$ grid cells in Europe (data from Dijkstra and Lewington, 2006). For the macrophytes of Switzerland, it was not quantified because of lack of information. For both dragonflies and macrophytes of France, the geographical distribution outside the study area was quantified by the number of counties of France currently occupied by a species (Grand and Boudot, 2006; Le réseau des Botanistes Francophones, 2010). For the dragonflies of South Africa, it was quantified by the number of African countries where a species occurred (Dijkstra et al., 2011).

Information about habitat vulnerability or species sensitivity to habitat disturbance was required for both the DBI and the nested ranking method. In France and Switzerland, it was quantified for dragonflies on the basis of the affinity of each species for 20 types of freshwater habitats (Dommanget (1998) adapted by C. Deliry, available in Rosset and Oertli (2011)) and for macrophytes on the basis of the presence of each species in 52 types of aquatic communities (Rodwell, 2000). For dragonflies of South Africa, categories of species' sensitivity to habitat disturbance were distinguished on the basis of species' sensitivity to habitat change due to alien species and of species occurrence in disturbed water bodies according to the South African dragonfly database (Samways, 2008; Simaika and Samways, 2009a; Samways and Simaika, unpublished detailed database).

The way that the different sub-indices of each scoring method are calculated may vary depending on the data available in a particular study area for each biological group. Such variability does not strongly affect the conclusions of the present paper, because it compares the conservation values given by the different scoring methods for a particular group in a particular study area and not among the biological groups or among the study areas.

\section{Statistical analyses}

Differences and similarities among the conservation values calculated with the four types of scoring methods, as well as with species richness, were explored through Spearman-rank correlations using XL-STAT version 2011.1.05. In order to clarify further the differences among methods, their ability to measure biotope quality (i.e. the quality of pond habitats and pond surroundings) was assessed according to the method used by Barbour et al. (1996), US EPA (1998) and Hering et al. (2006). These authors evaluated the fresh waters of North America and Europe in the context of the Clean 
Water Act and the Water Framework Directive, respectively. The principle of this method is to compare the number of sites classified as having very high/very low biotope quality by each type of scoring method with the number of sites classified as very high/very low biotope quality according to an independent assessment. This method was applied to the Swiss and French data sets. The independent assessment of the quality of 18 of the Swiss ponds was based on seven biological and environmental criteria confirmed by expert opinion (Menetrey et al., 2010). The independent assessment of the quality of 25 of the French ponds was based on expert opinion and on two criteria specific to these ponds, i.e. fishfarming practices and ecosystem equilibrium (Vallod et al., unpublished data). Ponds with conservation values above the 25th percentile of reference high quality sites were classified as "very high biotope quality' sites, and ponds with conservation values under the 75th percentile of low quality sites were defined as 'very low biotope quality' sites.

\section{RESULTS}

\section{Comparing the conservation values derived from the different types of scoring methods}

Most of the conservation values of adult dragonfly and macrophyte assemblages were significantly correlated among each other (exceptions described below), but at different strengths (minimum: 0.29; maximum: 0.99) (Table 3, Table 4). Overall, the correlations between the conservation values were moderate (mean Spearman $\rho$ of 0.54 for adult dragonflies and 0.75 for macrophytes).

As expected, when considering the scoring methods based exclusively on the Red List (the C value, the Csp value and the Aqua method), the correlations between

Table 3. Correlations (Spearman's rank) between the conservation values of dragonfly assemblages from Switzerland (upper value), France (middle value) and South Africa (bottom value) indicated by the different types of methods. Significant correlations: $* * P<0.01$, $* * * * ~ P<0.0001$. 'RL' corresponds to methods based exclusively on the Red List, 'RL + others' to methods coupling the Red List with other criteria, and 'others' to methods independent of the Red List. 'assembl.' corresponds to methods expressed per assemblage and 'sp.' to methods expressed per species

\begin{tabular}{|c|c|c|c|c|}
\hline RL, assembl. Aqua & $\begin{array}{l}0.665 * * * * \\
0.905 * * * * \\
0.619 * * * *\end{array}$ & & & \\
\hline RL, sp. Csp & $\begin{array}{l}0.731 * * * * \\
0.831 * * * * \\
0.593 * * * *\end{array}$ & $\begin{array}{l}0.915 * * * * \\
0.963 * * * * \\
0.991 * * * *\end{array}$ & & \\
\hline $\mathrm{RL}+$ others, sp. DBI & $\begin{array}{l}0.205 \\
0.794 * * * * \\
0.369 * * * *\end{array}$ & $\begin{array}{l}0.442 * * * * \\
0.761 * * * * \\
0.582 * * * *\end{array}$ & $\begin{array}{l}0.538 * * * * \\
0.731 * * * * \\
0.585 * * * *\end{array}$ & \\
\hline \multirow[t]{2}{*}{ others, sp. nested ranking } & $\begin{array}{l}-0.023 \\
0.616^{* * * *} \\
-0.073\end{array}$ & $\begin{array}{l}0.187 \\
0.513^{* * * *} \\
0.053\end{array}$ & $\begin{array}{l}0.294 * * \\
0.444 * * * * \\
0.066\end{array}$ & $\begin{array}{l}0.723 * * * * \\
0.832 * * * * \\
0.305 * *\end{array}$ \\
\hline & RL, assembl. C & RL, assembl. Aqua & RL, sp. Csp & RL + others, sp. DBI \\
\hline
\end{tabular}

Table 4. Correlations (Spearman's rank) between the conservation values of macrophyte assemblages from Switzerland (upper value) and France (bottom value) indicated by the different types of methods. Significant correlations: **** $P<0.0001$. 'RL' corresponds to methods based exclusively on the Red List, 'RL + others' to methods coupling the Red List with other criteria, and 'others' to methods independent of the Red List. 'assembl.' corresponds to methods expressed per assemblage and 'sp.' to methods expressed per species

\begin{tabular}{|c|c|c|c|c|}
\hline RL, assembl. Aqua & $\begin{array}{l}0.949 * * * * \\
0.769 * * * *\end{array}$ & & & \\
\hline RL, sp. Csp & $\begin{array}{l}0.714 * * * * \\
0.799 * * * *\end{array}$ & $\begin{array}{l}0.865^{* * * *} * \\
0.714 * * * *\end{array}$ & & \\
\hline $\mathrm{RL}+$ others, sp. DBI & $\begin{array}{l}0.470 * * * * \\
0.773 * * * *\end{array}$ & $\begin{array}{l}0.575 * * * * \\
0.641 * * * *\end{array}$ & $\begin{array}{l}0.708 * * * * \\
0.839 * * * *\end{array}$ & \\
\hline others, sp. nested ranking & $\begin{array}{c}\text { NA } \\
0.789^{* * * *}\end{array}$ & $\begin{array}{c}\text { NA } \\
0.703^{* * * *}\end{array}$ & $\begin{array}{c}\text { NA } \\
0.805^{* * * *}\end{array}$ & $\begin{array}{c}\text { NA } \\
0.913^{* * * *}\end{array}$ \\
\hline
\end{tabular}

RL, assembl. C RL, assembl. Aqua

RL, sp. Csp

$\mathrm{RL}+$ others, sp. DBI 
the scores were all high $(0.59<$ Spearman $\rho<0.99)$. The macrophytes were the exception in the French data set with the strongest correlation (Spearman $\rho=0.91$ ) occurring between the conservation value indicated by the method that coupled the Red List with other criteria (DBI), and the one obtained independently of the Red List (nested ranking method) (Table 4). The scoring method independent of the Red List, in this case the nested ranking method, produced scores that were the most weakly correlated with the others for adult dragonflies $(-0.02<$ Spearman $\rho<0.83$ ). For adult dragonflies in the Swiss and African data sets, the correlations were particularly weak, with half of the correlations non-significant. However, for macrophytes, the method independent of the Red List produced scores more strongly correlated with the others $(0.70<$ Spearman $\rho<0.91)$. The scoring method that coupled the Red List with other criteria, in this case the DBI, produced scores showing intermediate correlations with the other conservation values $(0.21<$ Spearman $\rho<0.83$ for dragonflies and $0.47<$ Spearman $\rho<0.84$ for macrophytes). For adult dragonflies of the Swiss data set, the conservation value obtained with this method was not significantly correlated with the $\mathrm{C}$ value.

Considering the way the conservation values are expressed (by assemblage or by species), the values expressed per species - in this case the Csp value, the DBI and the nested ranking method-were not, on average, more correlated among each other than with the other values expressed per assemblage, the $\mathrm{C}$ value and the Aqua (mean Spearman $\rho$ of 0.50 versus 0.53 for adult dragonflies and of 0.71 versus 0.82 for macrophytes).

\section{Relationship between the different types of conservation values and species richness}

The different types of conservation values were mostly significantly correlated with species richness in the three study areas, but with different levels of strength (minimum: 0.20; maximum: 0.95) (Table 5). Overall, the strength of the correlations between the values given by the different types of methods and species richness was not particularly strong (mean Spearman $\rho$ of 0.50 ). Two conservation values expressed per species were not significantly correlated with species richness in the Swiss and South African data set. These were (i) the DBI method which couples the Red List with other criteria and (ii) the nested ranking method, which is independent of the Red List.

The conservation values based exclusively on the Red List (the $\mathrm{C}$ value, the Csp value and the Aqua method) were correlated with species richness in a similar way to the other types of methods (the DBI and the nested ranking method).

The conservation values obtained through the two methods expressed per assemblage (the $\mathrm{C}$ value and the Aqua system) showed the highest correlations with species richness for both dragonflies and macrophytes in all study areas $(0.86<$ Spearman $\rho<0$. 95 and $0.26<$ Spearman $\rho<0$. 75). All other significant correlations between conservation values and species richness were weaker $(0.20<$ Spearman $\rho<0.66)$.

\section{Ability of the different types of conservation values for measuring biotope quality}

For both the dragonflies and macrophytes datasets from Switzerland and France the conservation values indicated by the different scoring methods were able to detect biotope quality in $11-85 \%$ of cases (Table 6). Species richness was able to detect biotope quality in $53-84 \%$ of cases (average $71 \%$ ) and was more powerful than any conservation value.

There were no differences in ability to measure biotope quality according to the weight given to the Red List. The conservation values based exclusively on the Red List (the $\mathrm{C}$ value, the Csp value and the Aqua method) did not perform

Table 5. Correlations (Spearman's rank) between the species richness and the conservation values indicated by the different scoring methods for dragonfly and macrophyte assemblages from France, Switzerland and South Africa. Significant correlations: $* * \quad P<0.01$, $* * * * ~ P<0.0001$. 'RL' corresponds to methods based exclusively on the Red List, 'RL + others' to methods coupling the Red List with other criteria, and 'others' to methods independent of the Red List. 'assembl.' corresponds to methods expressed per assemblage and 'sp.' to methods expressed per species

\begin{tabular}{|c|c|c|c|c|c|c|}
\hline \multirow[b]{2}{*}{ Type of method } & \multirow[b]{2}{*}{ Example } & \multicolumn{2}{|c|}{ France } & \multicolumn{2}{|c|}{ Switzerland } & \multirow{2}{*}{$\begin{array}{c}\text { South Africa } \\
\text { dragonflies }\end{array}$} \\
\hline & & dragonflies & macrophytes & dragonflies & macrophytes & \\
\hline RL, assembl. & Aqua & $0.623 * * * *$ & $0.745 * * * *$ & $0.423 * * * *$ & $0.697 * * * *$ & $0.258 * *$ \\
\hline $\mathrm{RL}, \mathrm{sp}$ & Csp & $0.475^{* * * *}$ & $0.616 * * * *$ & $0.508 * * * *$ & $0.320 * *$ & $0.201 * *$ \\
\hline RL + others, sp. & DBI & $0.609 * * * *$ & $0.611 * * * *$ & 0.041 & 0.171 & 0.139 \\
\hline others, sp. & nested ranking & $0.588 * * * *$ & $0.660 * * * *$ & -0.080 & - & -0.131 \\
\hline
\end{tabular}


Table 6. Percentage of sites for which the biotope quality was correctly detected by the different conservation values and by the species richness for dragonflies and macrophytes from France and Switzerland (18 sites for France and 25 sites for Switzerland). 'RL' corresponds to methods based exclusively on the Red List, 'RL + others' to methods coupling the Red List with other criteria, and 'others' to methods independent of the Red List. 'assembl.' corresponds to methods expressed per assemblage and 'sp.' to methods expressed per species

\begin{tabular}{|c|c|c|c|c|c|}
\hline \multirow[b]{2}{*}{ Type of method } & \multirow[b]{2}{*}{ Example } & \multicolumn{2}{|c|}{ France } & \multicolumn{2}{|c|}{ Switzerland } \\
\hline & & dragonflies & macrophytes & dragonflies & macrophytes \\
\hline RL, assembl. & $\mathrm{C}$ & 49 & 60 & 49 & 72 \\
\hline RL, assembl. & Aqua & 45 & 85 & 14 & 77 \\
\hline $\mathrm{RL}, \mathrm{sp}$ & Csp & 30 & 55 & 14 & 56 \\
\hline $\mathrm{RL}+$ others, sp. & DBI & 35 & 45 & 32 & 44 \\
\hline others, sp. & nested ranking & 50 & 60 & 11 & - \\
\hline species richness & - & 53 & 75 & 72 & 84 \\
\hline
\end{tabular}

better or worse than the conservation value coupling the Red List with other criteria (the DBI), or the conservation value independent of the Red List (the nested ranking method).

When considering the way the conservation values are expressed (by assemblage or by species), the conservation values expressed per assemblage and previously demonstrated to be highly correlated with species richness (the $\mathrm{C}$ value and the system Aqua) were the most sensitive in detecting biotope quality (on average 57\% and 55\% cases, respectively).

\section{DISCUSSION}

\section{Comparison of the different types of scoring methods}

The weight given to the Red List by the different types of scoring methods had a marked impact on the assessment of the conservation value of a particular pond. The scoring methods based exclusively on the Red List gave strongly correlated conservation values. This situation was to be expected because these methods rely entirely on the same data source, the Red List, to assess the conservation value. The relationship of these scoring methods with other methods, either coupling the Red List with other criteria, or independent of the Red List, was distinctly weaker. In contrast, the way the conservation values are expressed (per assemblage or per species), in contrast, did not have any impact on the strength of the correlations between conservation values. The conservation values expressed per species were not more highly correlated with each other than with the conservation values expressed per assemblage.

\section{Do the different types of scoring methods provide additional information over species richness?}

Some of the types of scoring methods showed a potential to provide additional information over species richness, while others did not. The scores obtained through methods expressed per assemblage were most strongly correlated with species richness, and this was mostly the case in all study areas, and for both macrophytes and dragonflies. This high correlation can be explained by the fact that, as with methods expressed per assemblage, each species, whether Red Listed or not, increases the conservation value. Therefore, conservation values expressed per assemblage provide very little extra information over species richness. Calculation of this type of conservation value appears to be an unnecessary step in the assessment of the conservation value of water bodies.

In contrast, the conservation values expressed per species do provide additional information over species richness assessments. Indeed, conservation values expressed per species were weakly correlated or not correlated at all with species richness. Such weak correlations have already been demonstrated for the DBI in South African rivers (Simaika and Samways, 2011) and for the Csp value in Switzerland (Oertli et al., 2002). These large differences between the conservation value and species richness confirm that measuring the conservation value of a site per species could provide additional information over measurement of species richness, while also revealing perspectives on species composition.

In summary, the way the conservation values are expressed (per assemblage or per species) has a marked impact on the strength of the correlation with species richness, and the conservation values expressed per assemblage brought no additional information over species richness. This high redundancy suggests that there is no need to use conservation values expressed per assemblage, but that using conservation values expressed per species is useful in assessing water bodies. 
The added usefulness of using scoring methods assessing conservation values over species richness for measuring biotope quality

In this study, species richness alone was a better metric than any measure of conservation value for describing biotope quality. Although not as powerful as species richness, scores for conservation value expressed per assemblage were more powerful for assessing biotope quality than scores for conservation value expressed per species. Evidently, the good performance of methods expressed per assemblage is directly related to their strong correlation with species richness.

These results suggest that conservation values are only weakly related with biotope quality, and therefore, that a biotope of poor quality can, surprisingly, host communities of high value. Part of the explanation could lie in potential large differences in the autecology of rare species (e.g. contrasting habitat or water quality requirements). The fact that conservation value appeared to be a weak indicator of biotope quality, in contrast to species richness, is consistent with the previously demonstrated ecological significance of species richness, which is frequently highly related to abiotic stresses that affect freshwater ecosystems (Bornette et al., 1998, 2001; Riis and Sand-Jensen, 2001; Hinden et al., 2005).

\section{Geographical and ecological limits to the applicability of the different types of scoring methods}

The different scoring methods of conservation value investigated here were developed in specific countries (Switzerland, France, Sweden, South Africa and UK) and have not previously been tested in other geographical areas. The mechanics of the different types of scoring methods suggests that they can be readily transferred from the specific context of one country to another, as well as from one particular taxonomic group to another; this transferability is confirmed by the present study. The different methods were also tolerant of the particularities and constraints of each geographical species pool. The only limitation to worldwide applicability is the availability of information concerning the regional species pool of a particular area (e.g. Red Lists, geographical distribution, ecological information). The present investigation also showed that the different scoring methods can easily be transferred among different types of standing water bodies (e.g. small lakes, fish ponds, reservoirs).
Recommendations on assessing the conservation value of water-body biodiversity

The results of this study indicated that, when evaluating an ecosystem, two indices should be used. First, species richness should be used because, at 'equal species interest', sites with high species richness have a higher priority in terms of conservation than those with low species richness. In addition, species richness gave the best performance for measuring biotope quality. Second, a scoring method of conservation value should also be used so that, in cases (for example) of equal species richness, priority species can be highlighted. Among the four types of methods tested, the conservation values expressed per assemblage should not be used, not because of any lack of power, but because of redundancy with species richness. The three remaining types of scoring methods, all the ones expressed per species, provided additional information over that of species richness. They produced sets of conservation values (for dragonfly and macrophyte assemblages) that were moderately correlated with each other. This suggests that each provides different information about the conservation value of an ecosystem, reinforcing the need for recommendations concerning their use.

We therefore underline here some methodological differences which could help nature managers and environmental consultants tailor the choice of a type of conservation value(s) (Table 7). First, the scoring methods based only on the Red List are faster to calculate than the other methods that require additional criteria. Then, two types of conservation values (combining the Red List with other criteria and independent from the Red List) have a larger spread of values, when many species are of Least Concern (LC) status. This could have the advantage of classifying more precisely sites that have only LC species, and have the same conservation value when using methods based exclusively on the Red List. Finally, the conservation values independent of the Red List have the disadvantage of not taking into consideration continuing changes in species' population size at the regional scale. It assigns the same conservation value to a species currently rare but stable or in decline, as one currently rare but increasing in abundance (due to climate change for example). All the other types of scoring methods indirectly incorporate this aspect, which is taken into account in the Red List. 
Table 7. Criteria which could help nature managers and environmental consultants in choosing among three different types of scoring methods for conservation value. The methods expressed per assemblage have been discarded because of their high redundancy with species richness (see Discussion for more details). 'RL' corresponds to methods based exclusively on the Red List, 'RL + others' to methods coupling the Red List with other criteria, and 'others' to methods independent of the Red List. 'assembl.' corresponds to methods expressed per assemblage and 'sp.' to methods expressed per species

\begin{tabular}{|c|c|c|c|}
\hline & $\mathbf{R L}$ & RL + others & others \\
\hline Example (method tested in the present study) & Csp value & DBI & nested ranking \\
\hline Time to compute & short & long & long \\
\hline Values spread on a large gradient (even when many species without RL status) & no & yes & yes \\
\hline Calculation using knowledge on the trend in species' population size & yes & yes & no \\
\hline
\end{tabular}

In conclusion, the methods expressed per species and coupling the Red List with other criteria, for example the DBI, give the best performance. Where there are financial limitations for an assessment, the methods expressed per species and based exclusively on the Red List, even if performing less well, could be used because of their ease of calculation. The selection of a type of method also depends on the species information available (i.e. Red List status, geographical distribution, ecology). Where there is a lack of information on species' habitat vulnerability or species' sensitivity to habitat disturbance, the methods expressed per species and based exclusively on the Red List would be the only option. In the case of imprecise Red List assessments or absence of Red List assessments, the methods expressed per species and independent of the Red List would be preferred.

\section{ACKNOWLEDGEMENTS}

We thank the numerous people from the University of Geneva (Laboratory of Ecology and Aquatic Biology), the University of Applied Sciences Western Switzerland (hepia, Geneva), ISARA-Lyon (Engineering school in agriculture, alimentation, rural development and environment), the Lyon 1 University (UMR CNRS 5023, laboratory of ecology of natural and anthropized hydrosystems), Stellenbosch University (Department of Conservation Ecology and Entomology) for the fieldwork, the laboratory work and database management. We acknowledge the wide support given to gathering information from the databases of the Swiss and French ponds, in particular by the University of Applied Sciences of Western Switzerland (RCSO RealTech), and also the French-Swiss PHC Germaine de Staël grant (see Rosset et al. (2010) and Arthaud et al. (in press) for a complete list of financial support). Véronique Rosset's visits to South Africa were supported by the Swiss-South African Joint Research Programme, the international relations HES-SO, the Swiss Society of Hydrology and Limnology SGHL, and a grant from the Swiss Academy of Technical Sciences. John Simaika was supported by a Natural Sciences and Engineering Research Council of Canada (NSERC) PGS-D3 scholarship, and Michael Samways by the National Research Foundation, South Africa.

We also would like to thank the anonymous reviewers for their insightful comments which helped to improve the manuscript, P. Nicolet and J. Park for editing the English and D. Leclerc for scanning raw data.

\section{REFERENCES}

Amoros C, Bornette G, Henry CP. 2000. Environmental auditing. A vegetation-based method for ecological diagnosis of riverine wetlands. Environmental Management 25: $211-227$.

Angelibert S, Indermuehle N, Luchier D, Oertli B, Perfetta J. 2006. Where hides the aquatic biodiversity of macroinvertebrates in the Canton of Geneva (Switzerland)? Archives Des Sciences 59: 225-234.

Angermeier PL, Winston MR. 1997. Assessing conservation value of stream communities: a comparison of approaches based on centres of density and species richness. Freshwater Biology 37: 699-710.

Arthaud F, Vallod D, Robin J, Bornette G. in press. Eutrophication and drought disturbance shape functional diversity and life-history traits of aquatic plants in shallow lakes. Aquatic Sciences.

Auderset Joye D, Schwarzer A, Lachavanne J-B, Juge R. 2010. Liste rouge des Characées - Liste rouge des espèces menacées en Suisse. Office fédéral de l'environnement, Berne et Laboratoire d'écologie et biologie aquatique, Université de Genève, Berne.

Barbour MT, Gerritsen J, Griffith GE, Frydenborg R, McCarron E, White JS, Bastian ML. 1996. A framework for biological criteria for Florida streams using benthic macroinvertebrates. Journal of the North American Benthological Society 15: 185-211. 
Biggs J, Williams P, Whitfield M, Nicolet P, Weatherby A. 2005. 15 years of pond assessment in Britain: results and lessons learned from the work of Pond Conservation. Aquatic Conservation: Marine and Freshwater Ecosystems 15: 693-714.

Boon PJ. 2000. The development of integrated methods for assessing river conservation value. Hydrobiologia 422/423: 413-428.

Boon PJ, Holmes NTH, Maitland PS, Rowell TA, Davies J. 1997. A system for evaluating rivers for conservation ('SERCON'): development, structure and function. In Freshwater Quality: Defining the Indefinable? The Stationery Office: Edinburgh; 299-326.

Boon PJ, Pringle CM. 2009. Assessing the Conservation Value of Fresh Waters. an International Perspective. Cambridge University Press: Cambridge.

Boon PJ, Holmes NTH, Maitland PS, Fozzard IR. 2002. Developing a new version of SERCON (system for evaluating rivers for conservation). Aquatic Conservation: Marine and Freshwater Ecosystems 12: 439-455.

Bornette G, Amoros C, Lamouroux N. 1998. Aquatic plant diversity in riverine wetlands: the role of connectivity. Freshwater Biology 39: 267-283.

Bornette G, Piégay H, Citterio A, Amoros C, Godreau V. 2001. Aquatic plant diversity in four river floodplains: a comparison at two hierarchical levels. Biodiversity and Conservation 10: 1683-1701.

Brönmark C, Hansson LA. 2002. Environmental issues in lakes and ponds: current state and perspectives. Environmental Conservation 29: 290-307.

Chadd R, Extence C. 2004. The conservation of freshwater macroinvertebrate populations: a community-based classification scheme. Aquatic Conservation: Marine and Freshwater Ecosystems 14: 597-624.

Copp GH, Serhan Tarkan AS, Godard MJ, Edmonds NJ, Wesley KJ. 2010. Preliminary assessment of feral goldfish impacts on ponds, with particular reference to native crucian carp. Aquatic Invasions 5: 413-422.

Davies B, Biggs J, Williams P, Whitfield M, Nicolet P, Sear D, Bray S, Maund S. 2008. Comparative biodiversity of aquatic habitats in the European agricultural landscape. Agriculture, Ecosystems and Environment 125: 1-8.

Dijkstra KDB, Lewington R. 2006. Field Guide to the Dragonflies of Britain and Europe. British Wildlife Publishing: Gillingham.

Dijkstra KDB, Boudot J-P, Clausnitzer V, Kipping J, Kisakye JJ, Ogbogu SS, Samraoui B, Samways MJ, Schutte K, Simaika JP, et al. 2011. Dragonflies and damselflies of Africa (Odonata): history, diversity, distribution, and conservation. In The Diversity of Life in African Freshwaters: Underwater, Under Threat, Darwall W, Smith K, Allen D, Holland R, Harrison I, Brooks E (eds). IUCN: Gland, Switzerland and Cambridge, UK; 126-173.

Dommanget J-L. 1998. Les Libellules et Leurs Habitats. Société Française d'Odonatologie: Bois-d'Arcy.

Downing JA, Prairie YT, Cole JJ, Duarte CM, Tranvik LJ, Striegl RG, McDowell WH, Kortelainen P, Caraco NF, Melack JM, et al. 2006. The global abundance and size distribution of lakes, ponds, and impoundments. Limnology and Oceanography 51: 2388-2397.

Duker L, Palmer M. 2009. Methods for assessing the conservation value of lakes. In Assessing the Conservation Value of Fresh Waters. An International Perspective, Boon PJ, Pringle CM (eds). Cambridge University Press: Cambridge; 166-199.

EPCN. 2007. Developing the Pond Manifesto. Annales De Limnologie - International Journal of Limnology 43: 221-232.
Fleishman E, Noss RF, Noon BR. 2006. Utility and limitations of species richness metrics for conservation planning. Ecological Indicators 6: 543-553.

Foster GN, Foster AP, Eyre MD, Bilton DT. 1989. Classification of water beetle assemblages in arable fenland and ranking of sites in relation to conservation value. Freshwater Biology 22: 343-354.

Foster GN, Nelson BH, Bilton DT, Lott DA, Merritt R, Weyl RS, Eyre MD. 1992. A classification and evaluation of Irish water beetle assemblages. Aquatic Conservation: Marine and Freshwater Ecosystems 2: 185-208.

Gauthier P, Debussche M, Thompson JD. 2010. Regional priority setting for rare species based on a method combining three criteria. Biological Conservation 143: 1501-1509.

Godreau V, Bornette G, Frochot B, Amoros C, Castella E, Oertli B, Chambaud F, Oberti D, Craney E. 1999. Biodiversity in the floodplain of Saône: a global approach. Biodiversity and Conservation 8: 839-864.

Gonseth Y, Monnerat C. 2002. Liste rouge des espèces menacées en Suisse. Libellules. OFEFP \& CSCF: Berne and Neuchâtel, Switzerland.

Grand D, Boudot J-P. 2006. Les libellules de France, Belgique et Luxembourg. Biotope (Collection Parthénope): Mèze.

Hering D, Feld CK, Moog O, Ofenbock T. 2006. Cook book for the development of a multimetric index for biological condition of aquatic ecosystems: experiences from the European AQEM and STAR projects and related initiatives. Hydrobiologia 566: 311-324.

Hinden H, Oertli B, Menetrey N, Sager L, Lachavanne JB. 2005. Alpine pond biodiversity: what are the related environmental variables? Aquatic Conservation: Marine and Freshwater Ecosystems 15: 613-624.

Indermuehle N, Angélibert S, Rosset V, Oertli B. 2010. The pond biodiversity index "IBEM": a new tool for the rapid assessment of biodiversity in ponds from Switzerland. Part 2. Method description and examples of application. Limnetica 29: 105-119.

IUCN. 2001. IUCN Red List Categories and Criteria: version 3.1. IUCN Species Survival Comission: Gland, Switzerland and Cambridge, UK.

Jeffries M. 2005. Small ponds and big landscapes: the challenge of invertebrate spatial and temporal dynamics for European pond conservation. Aquatic Conservation: Marine and Freshwater Ecosystems 15: 541-547.

Kati V, Devillers P, Dufrene M, Legakis A, Vokou D, Lebrun P. 2004. Testing the value of six taxonomic groups as biodiversity indicators at a local scale. Conservation Biology 18: 667-675.

Le réseau des Botanistes Francophones. 2010. http://www. tela-botanica.org/page:eflore

Magurran AE. 2004. Measuring Biological Diversity. Blackwell Publishing: Oxford.

Menetrey N, Oertli B, Lachavanne JB. 2010. The CIEPT: a macroinvertebrate-based multimetric index for assessing the ecological quality of Swiss lowland ponds. Ecological Indicators 11: 590-600.

Millennium Ecosystem Assessment. 2005. Ecosystems and Human Well-Being: Wetlands and Water. Synthesis: Washington.

Moser DM, Gygax A, Bäumler B, Wyler N, Palese R. 2002. Liste rouge des espèces menacées de Suisse. Fougères et plantes à fleurs. Office fédéral de l'environnement, des forêts et du paysage: Berne; Centre du Réseau Suisse de Floristique: Chambésy; Conservatoire et Jardin botaniques de la Ville de Genève: Chambésy.

Nicolet P, Biggs J, Fox G, Hodson MJ, Reynolds C, Whitfield M, Williams P. 2004. The wetland plant and macroinvertebrate assemblages of temporary ponds in England and Wales. Biological Conservation 120: 261-278. 
Oertli B. 1995. Odonates de la vallée de la Saône. Martinia 11: $35-42$.

Oertli B, Auderset Joye D, Castella E, Juge R, Cambin D, Lachavanne J-B. 2002. Does size matter? The relationship between pond area and biodiversity. Biological Conservation 104: $59-70$.

Painter D. 1999. Macroinvertebrate distributions and the conservation value of aquatic Coleoptera, Mollusca and Odonata in the ditches of traditionally managed and grazing fen at Wicken Fen, UK. Journal of Applied Ecology 36: 33-48.

Ricciardi A, Rasmussen JB. 1999. Extinction rates of North American freshwater fauna. Conservation Biology 13: $1220-1222$.

Riis T, Sand-Jensen K. 2001. Historical changes in species composition and richness accompanying perturbation and eutrophication of Danish lowland streams over 100 years. Freshwater Biology 46: 269-280.

Rodwell JS. 2000. British Plant Communities: Aquatic Communities, Swamps and Tall-Herb Fens. Cambridge University Press: Cambridge.

Rosset V, Oertli B. 2011. Freshwater biodiversity under climate warming pressure: identifying the winners and losers in temperate standing waterbodies. Biological Conservation 144: 2311-2319.

Rosset V, Lehmann A, Oertli B. 2010. Warmer and richer? Predicting the impact of climate change on biodiversity in small temperate waterbodies. Global Change Biology 16: $2376-2387$.

Samways MJ. 2006. National Red List of South African dragonflies (Odonata). Odonatologica 35: 341-368.

Samways MJ. 2008. Dragonflies and Damselflies of South Africa. Pensoft Publishers: Sofia, Bulgaria.
Simaika JP, Samways MJ. 2009a. An easy-to-use index of ecological integrity for prioritizing freshwater sites and for assessing habitat quality. Biodiversity and Conservation 18: $1171-1185$.

Simaika JP, Samways MJ. 2009b. Reserve selection using Red Listed taxa in three global biodiversity hotspots: dragonflies in South Africa. Biological Conservation 142: 638-651.

Simaika JP, Samways MJ. 2011. Comparative assessment of indices of freshwater habitat conditions using different invertebrate taxon sets. Ecological Indicators 11: $370-378$.

US EPA. 1998. Lake and Reservoir Bioassessment and Biocriteria: Technical Guidance Document, EPA841-B-98-007, USA.

Vallod D, Wezel A, Robin J, Bornette G, Arthaud F, Oertli B, Rosset V, Angélibert S, Leclerc D, Wuillot J. 2011. Ecological assessment of ponds from the Dombes. Conception of an assessment method applicable to ponds. Report for the French Water Agency.

Willen E. 2009. System Aqua - a Swedish system for assessing nature conservation values of freshwaters. In Assessing the Conservation Value of Fresh Waters. An International Perspective, Boon PJ, Pringle CM (eds). Cambridge University Press: Cambridge.

Williams P, Biggs J, Whitfield M, Corfield A, Fox G, Adare K. 1998. Biological techniques of still water quality assessment. Phase 2. Method development. Technical Report E56. Environment Agency: Bristol.

Williams P, Whitfield M, Biggs J, Bray S, Fox G, Nicolet P, Sear D. 2004. Comparative biodiversity of rivers, streams, ditches and ponds in an agricultural landscape in Southern England. Biological Conservation 115: 329-341. 